\title{
El desafío de las concesiones de obra pública: ¿qué (y qué no) concesionar?
}

\author{
Martín Loo Gutiérrez*
}

\section{RESUMEN}

El trabajo busca explicitar los criterios para determinar el tipo de obras que pueden ser entregadas en concesión y establecer las herramientas con que cuenta la Administración Pública para verificar que los fines de las concesiones de obras públicas puedan alcanzarse con las obras que se decida concesionar.

Concesiones de obras públicas - asociaciones público privadas - Consejo de Concesiones

\section{The Challenge of Public Works Concessions: What (and What Not) to Concession?}

\begin{abstract}
The paper's aim is to put in evidence some criteria to decide which kind of projects can be the object of a public works concession contract. It shows legal mechanisms available to the public administration to verify whether or not a project can meet the aims of the public works concession contract.
\end{abstract}

Public works concessions - public private partnerships - Concessions Council

* Licenciado en Derecho, Pontificia Universidad Católica de Valparaíso. Doctor en derecho público, Universidad de Roma II - Tor Vergata, Italia. Profesor de derecho administrativo, Pontificia Universidad Católica de Valparaíso. Correo electrónico: martin.loo@pucv.cl

Trabajo financiado por la Comisión Nacional de Investigación Científica y Tecnológica mediante el Proyecto Fondecyt de Iniciación en la Investigación No 11160169/2016. Agradezco a la Prof. Dra. Blanca Rodríguez-Chaves Mimbrero la hospitalidad concedida por la Biblioteca de la Facultad de Derecho de la Universidad Autónoma de Madrid, lugar donde se desarrolló gran parte de este escrito. Agradezco a Rodrigo Bermúdez, Eduardo Bustamante y a los pares revisores las interesantes observaciones a las versiones preliminares de este artículo.

Artículo recibido el 15 de octubre de 2018 y aceptado para su publicación en este número el 1 de agosto de 2019. 


\section{INTRODUCCIÓN}

$\mathrm{E}$ 13 de julio de 2018 el diario La Tercera titulaba: "Minsal evalúa construir entre 13 y 17 hospitales, todos concesionados". La nota relataba que el ministro de Salud había señalado ante la Comisión de Salud de la Cámara de Diputados que los recintos hospitalarios "serán levantados bajo el sistema de concesiones, en una modalidad denominada Asociación Público Privada (APP), que restringe la acción de los privados a la edificación y mantención, excluyéndolos de la operación clínica que hoy existe en los recintos de Maipú y La Florida"1.

El contenido de la nota da cuenta de la confusión que existe en nuestro país acerca de los alcances, fines y modalidades que puede presentar el contrato de concesión de obra pública y qué implica que una obra pública se desarrolle bajo un sistema de "asociación público privada” (APP).

Como se ha intentado evidenciar en otro trabajo ${ }^{2}$, en nuestro entorno existe un déficit de reflexión jurídica acerca del contrato de concesión de obra pública y de sus diferentes modalidades de concreción práctica. Este déficit tiene impacto en el alcance que se quiere dar al sistema de concesiones, ya ampliando, ya restringiendo el número y tipo de obras sometidas a esta modalidad de ejecución de infraestructura. Este vaivén sigue el ritmo de los ciclos político-electorales y lesiona la estabilidad de las políticas públicas en materia de infraestructuras.

De esta manera, de tiempo en tiempo (más precisamente, luego de cada elección presidencial), se es testigo de polémicas políticas acerca de las obras públicas que "conviene” concesionar y de cómo este sistema de ejecución de obras ayudaría a subsanar las deficiencias estructurales del sistema de prestación de servicios públicos.

Es importante señalar que el sistema de concesiones podrá o no alcanzar sus fines dependiendo del tipo de obra pública que se desarrolle. Puede advertirse que las discusiones políticas acerca de qué se concesionará parecen desdeñar las directrices desarrolladas por la experiencia comparada para establecer qué objetivos resultan razonables, o siquiera, posibles de satisfacer con una concesión de obra pública o APP. En buenas cuentas, la determinación de qué tipo de proyecto se realizará mediante una concesión debiera ser la expresión de una política pública sustentada en razones de orden técnico.

En el presente artículo pretendo explorar las razones que se han elaborado en el extranjero para justificar las concesiones y las APP y, con ello, aportar algunas reflexiones a esta discusión. Entonces, los objetivos centrales de esta contribución son dos: primero, poner en evidencia algunos criterios para determinar las características de las obras y servicios públicos que la experiencia comparada considera "aptos" para ser dados en concesión o realizados mediante APP y, segundo, intentar reconocer si la Administración del Estado chilena cuenta con mecanismos idóneos para implementar los criterios que se identifiquen.

\footnotetext{
${ }^{1}$ La Tercera, 2018.

${ }^{2}$ Loo, 2019.
} 
Para alcanzar estos objetivos, en primer lugar, realizaré una breve recapitulación acerca de las principales características que deben tener las obras para ser consideradas aptas para ser dadas en concesión (II); luego revisaré los objetivos que la doctrina comparada ha identificado como propios de un sistema concesional (III) y, finalmente, analizaré algunas normas nacionales para establecer si la Administración del Estado cuenta con instrumentos suficientes para determinar si es posible alcanzar los objetivos antes individualizados (IV). Se ofrecerán unas breves conclusiones (V).

\section{UNA BREVE, PERO NECESARIA RECAPITULACIÓN}

Nuestra legislación no cuenta con una definición de las concesiones de obra pública ni de las APP.

Por de pronto, la expresión "asociación público privada" ha entrado en el lenguaje legislativo nacional solo recientemente, con motivo de la creación, por parte de la Ley $\mathrm{N}^{\circ} 21.044^{3}$, de la Dirección General de Concesiones de Obras Públicas del MOP, a cuyo director se atribuyó la competencia para "fomentar (...) la asociación público privada en materia de infraestructura" ${ }^{4}$. La norma, como vemos, se refiere a las APP, pero no formula alguna noción de las mismas.

A este respecto, es posible recordar que la expresión "asociación público privada" es conceptualmente imprecisa. Ello se debe a que, pese a los esfuerzos de concreción normativa de algunos países (España, Italia, Colombia y, recientemente, Argentina, solo por nombrar algunos), que han configurado legislativamente contratos de "colaboración” o de "asociación” público-privada, pareciera ser cierto que la denominación se ha difundido gracias a su utilización política y comunicacional más que por su (impreciso) significado jurídico. En otros términos, la expresión APP es una etiqueta que ha terminado aplicándose a un conjunto heterogéneo de relaciones jurídicas entre la Administración y agentes del sector privado, que incluyen -según sea quién utiliza la expresión- desde un "simple" contrato de obras públicas a figuras más complejas desde el punto de vista económico-financiero como el "leasing público" 5 .

La concesión de obra pública, en cambio, encuentra un mayor grado de determinación legislativa en los artículos 87 de la ley orgánica del MOP (D.F.L. MOP No 850 de 1997) y $1^{\circ}$ de la ley de concesiones de obras públicas (D.S. MOP N 900 de 1996, en adelante LCOP). La primera de estas normas dispone que la ejecución, reparación o mantención de las obras públicas fiscales de competencia del Ministerio de Obras Públicas puede ser realizada a cambio de la concesión temporal de su explotación. La segunda disposición, por su parte, fija el marco normativo del contrato de concesión de obras públicas.

\footnotetext{
${ }^{3}$ D. Of. 15.11 .2017$.

${ }^{4}$ Art. 22 ter letra f) de la ley orgánica del MOP.

5 Magide, 2016, p. 127. Sobre el “leasing público", Mairal, 2013, p. 203.
} 
A diferencia de cuanto ocurre en algunas legislaciones extranjeras ${ }^{6}$, ninguna de estas disposiciones contiene una noción del contrato de concesión de obra pública. En virtud de ellas, el legislador se limitó a autorizar al MOP para que la ejecución de las obras de su competencia pueda realizarse, también, en virtud de un contrato de construcción caracterizado por el especial modo de remuneración del contratista, esto es, por la concesión de la explotación de la obra realizada.

A pesar de lo anterior, de la legislación pertinente puede concluirse que el contrato de concesión de obra pública es aquel contrato administrativo que tiene por objeto la construcción, o bien, la reparación y, en ambos casos, el mantenimiento de una obra pública fiscal a cambio de la concesión temporal de su explotación.

Puede advertirse que los elementos centrales del contrato son dos: la obra pública fiscal y el derecho de explotación que compete al concesionario. La "obra pública fiscal" puede ser tanto construida como reparada por el contratista y, en todo caso, mantenida por el mismo con el objeto de hacer posible el ejercicio de su "derecho de explotación"; actividad que constituye la contraprestación por la realización o reparación de aquella ${ }^{7}$. En otras palabras, la obra pública construida o reparada por el concesionario constituye el sustento material del derecho de explotación ${ }^{8}$.

Las variaciones y modulaciones que tengan la "obra pública fiscal" y el "derecho de explotación” en cada específico contrato de concesión permiten afirmar la existencia de distintas especies del mismo, algunas de estas corresponden, en términos generales, a aquello que la doctrina extranjera denomina "asociaciones público privadas".

Por ello es que resulta necesario indagar, en primer lugar, el significado que nuestra legislación atribuye a la "obra pública fiscal", o sea, aquello que será construido o reparado y conservado por el concesionario.

El art. 39 LCOP (antiguo art. 38 LCOP, modificado por la Ley $\mathrm{N}^{\circ} 20.410$ ), no limita el objeto del contrato de concesión a la sola construcción, reparación y conservación de un bien inmueble, sino que amplía la noción de obra pública fiscal para abarcar actividades no constructivas, como son "la provisión de equipamiento o a la prestación de servicios asociados". Así, nuestra ley considera "obra pública fiscal” lo que la doctrina extranjera ha calificado como "infraestructura" por incorporar elementos no tangibles, así como la prestación de servicios?.

A partir de esta noción amplia del objeto material del contrato de concesión es posible que la Administración celebre contratos cuya finalidad no sea, únicamente, la construcción y explotación de un inmueble (la "obra pública fiscal” del viejo artículo 38 LCOP), sino que la concesión comprenda también la provisión de equipamiento y la prestación de servicios asociados a la naturaleza del inmueble que se ha construido o reparado.

\footnotetext{
${ }^{6}$ Por ejemplo, artículo 14, ley 9/2017 española; art. 3, apartado 1, letra 11) del Decreto legislativo No 50 de 2016 italiano; art. 32, ley 80/1993, colombiana, por citar solo algunas normas extranjeras.

${ }^{7}$ GuAsch, 2004, p. 26.

${ }^{8}$ Puerta Seguido, 2008, pp. 106-107.

${ }^{9}$ Villar EzCurra, 2004, p. 682.
} 
Este cambio resulta clave para comprender en qué consiste el contrato de concesión de obra pública en nuestra actual legislación y por qué razón ciertas modalidades del mismo son llamadas "asociaciones público privadas". Hace posible, por tanto, que en nuestra legislación se pueda hablar de concesiones y de APP como dos nociones interdependientes, pero distinguibles.

Como ya puede advertirse, la naturaleza de la obra pública condiciona la modalidad de su explotación. Por tanto, corresponde que se haga referencia al segundo aspecto central del contrato de concesión: el "derecho de explotación" del concesionario.

En las concesiones, el contratista obtiene su remuneración de la gestión económicacomercial de la infraestructura. Esto es llamado "explotación de la concesión”. La forma de esta explotación y, con ello, el receptor de los servicios que se presten con la infraestructura se encuentra indisolublemente ligada al tipo de inmueble que se construya. Por otro lado, el receptor de los servicios, por lo general -aunque no siempre-, determinará el sujeto obligado a pagar por el uso de la infraestructura. De este modo, se tienen dos posibilidades: la obra pública construida podrá ser destinada al uso de la población o al uso de la misma Administración Pública.

En el primer caso, la comunidad podrá acceder libremente a la utilización de la obra pública, pagando por ello. Este tipo de explotación es conocido como "pago por uso" y corresponde a la forma original y paradigmática del contrato de concesión de obras. Se trata de la modalidad utilizada generalmente en las infraestructuras de transporte, como las autopistas y los aeropuertos, las que son explotadas mediante la prestación de servicios a terceros ajenos a la relación contractual entre el Estado y el concesionario quienes, por su parte, pagan por dicho uso.

En el segundo caso, el concesionario desarrolla infraestructura que solo puede ser destinada a la Administración, quien, a su vez, utilizará la obra para prestar un servicio público o para servirse directamente de ella. En esta situación ya no será posible que la explotación consista en el cobro que se realice a los destinatarios del servicio (i.e. la comunidad), porque su única usuaria será la Administración, la que pagará un subsidio o canon destinado a remunerar tanto la realización de la infraestructura como la prestación de servicios del concesionario ${ }^{10}$.

En este tipo de infraestructuras el concesionario presta un tipo de servicio cuyo único (posible) usuario es el órgano del Estado que requiere de la obra pública. Así, el único demandante del servicio de alimentación (o de lavandería o de actividades de reinserción social, etc.) de internos en un centro penitenciario concesionado es, precisamente, el órgano encargado de prestar estos servicios, esto es, Gendarmería de Chile, la

${ }^{10}$ Conviene dejar establecido que este tipo de contrato de concesión de obra pública se distingue del contrato de obra pública precisamente por prever como obligación del concesionario la prestación de servicios a favor de la Administración y, a su vez, se diferencia del contrato de prestación de servicios por llevar envuelta la obligación de construcción de una obra pública. 
que pagará una remuneración por los servicios, así como subsidios por la construcción, realizándose con ello la "explotación" de la obra pública ${ }^{11}$.

Esta última modalidad de concesión es la que, en el extranjero, se denomina "asociación público privada”. Así, según la doctrina española, estas APP se caracterizan por tres notas fundamentales: primero, la activa participación del contratista privado en la definición del proyecto; segundo, la gestión de la obra pública o del equipamiento público, no directamente para los particulares, sino para la propia Administración, que utiliza la infraestructura como base física de la prestación de servicios públicos a los ciudadanos y, tercero, la retribución del contratista no es abonada directamente por los usuarios, sino por la propia Administración ${ }^{12}$.

Este tipo de contratos es utilizado para la realización de infraestructuras destinadas a la provisión de servicios caracterizados por su elevada complejidad ${ }^{13}$, cuestión que se traduce en una mayor dificultad de fiscalización de su calidad por parte del órgano concedente.

Por ello es que he afirmado, siguiendo la doctrina económica, que la clave para determinar cuándo resulta apropiada una concesión se encuentra en establecer el tipo de proyecto o infraestructura que se desarrollará, debiendo privilegiarse, como veremos, las obras que presten un servicio cuya calidad sea fácil de medir y fiscalizar y en las que el aumento de eficiencia del concesionario no impacte en la calidad de los mismos ${ }^{14}$.

Corresponde preguntarse, por esta razón, qué hace que una infraestructura con unas ciertas características sea más propicia para ser llevada a cabo por medio de una concesión que mediante provisión estatal (esto es, por medio de un contrato de obras) y, por el contrario, qué hace que una obra destinada a prestar servicios de una determinada mayor complejidad sea poco adecuada para ser desarrollada por medio de APP.

En el siguiente apartado se intentará sistematizar los objetivos que la literatura comparada sostiene que es posible satisfacer por medio de las concesiones. Ello dará paso a analizar qué tipo de infraestructura puede satisfacer dichos objetivos.

\section{LOS OBJETIVOS DE UN SISTEMA CONCESIONAL}

La determinación de los objetivos de las concesiones de obra pública es un aspecto clave para establecer qué tipo de infraestructura será concesionada y, con ello, el tipo de servicios que dichas obras públicas prestarán. En la literatura se encuentran algunos criterios para discernir qué clase de infraestructura logrará satisfacer los objetivos de las concesiones.

${ }^{11}$ Una muy fundada crítica al sistema de concesiones de recintos penitenciarios, puede encontrarse en RAMÍrEZ BARría, 2018.

\footnotetext{
${ }^{12}$ Magide, 2016, p. 130.

13 Davies, 2001, p. 3.

${ }^{14}$ Engel et al., 2014, p. 209.
} 
Hay que advertir que la valoración de estas directrices es una actividad política ${ }^{15}$. No es posible enunciar criterios estrictamente legales que permitan determinar cuándo una cierta obra puede, o no, ser dada en concesión. En otras palabras, no existen en la legislación pautas prescriptivas que permitan a la Administración discernir qué puede ser concesionado y qué no. Por ello, la Administración se verá limitada a llevar a la práctica las decisiones de las autoridades políticas.

No obstante lo anterior, creo que resulta imprescindible estudiar los criterios desarrollados por la experiencia comparada, ya que ellos admiten ser replicados en nuestra realidad resultando útiles para orientar las decisiones políticas, las que pueden echar mano a insumos relevantes de la experiencia internacional respecto del éxito o fracaso de los proyectos concesionados.

En efecto, en el extranjero parece haberse formado un consenso relativamente amplio acerca de las "bondades" que justificarían la realización de obras públicas por medio de APP, siendo posible identificar algunos objetivos que se pueden alcanzar mediante ellas. Así, se sostiene que las APP serían capaces de entregar mediante beneficios que las harían "mejores" que la opción tradicional del contrato de obra pública en una serie de dimensiones.

Las dimensiones que se tomarán en consideración en este trabajo son tres: primero, la posibilidad de financiar obras públicas con recursos privados y el efecto de adicionalidad que ello supondría ${ }^{16}$; segundo, la aparente mayor eficacia del sector privado en estas tareas ${ }^{17}$ y tercero, los beneficios que comporta la integración de tareas en un solo contratista, cuestión que haría que las APP entreguen un mejor value for money ${ }^{18}$.

En lo sucesivo, se someterán a revisión crítica estas asunciones con el fin de establecer cuáles son las razones que justificarían proceder a una concesión o a una APP.

\section{Financiación privada de infraestructura y el efecto de "adicionalidad"}

La ejecución de infraestructura mediante concesiones (o de APP) importa, en primer término, que la obra pública será financiada por el sector privado, ya que el financiamiento de las obras es una de las obligaciones que surgen para la sociedad concesionaria ${ }^{19}$.

En la experiencia extranjera es posible advertir que la captación de financiamiento privado es el objetivo primordial de las $\mathrm{APP}^{20}$. Es el caso de la política inglesa conocida

15 P.e., para Grimsey y LeWis, 2004, p. 128.

${ }^{16}$ Engel et al., 2014, p. 29; Yescombe, 2007, p. 17.

17 Yescombe, 2007, 21; Grimsey y Lewis, 2004, 32; Engel et al., 2001, 203 cuestión que evitaría la construcción de 'elefantes blancos', o sea, obras inútiles: ENGEL et al., 2014, p. 34; SADKA, 2006, p. 8; Yescombe, 2007, p. 21.

${ }^{18}$ House of Lords, Select Committee on Economic Affairs, 2010, p. 21; Yescombe, 2007, p. 18.

${ }^{19}$ Ministerio de Obras Públicas, 2016, p. 21.

${ }^{20}$ También puede identificarse un objetivo de disciplina fiscal, especialmente, en la Unión Europea. Vid. Loo Gutiérrez, 2015. 
como Private Finance Initiative (PFI), en la que el sector privado aporta la financiación de infraestructura pública por medio de endeudamiento de la sociedad concesionaria.

Esta política, cuando surgió, "admitió la realización de todo proyecto financiado privadamente que pudiera ser operado rentablemente" ${ }^{21}$. La literatura comparada es explícita al reconocer que el fin primordial de la PFI fue, precisamente, la movilización de recursos privados para el desarrollo de infraestructura pública ${ }^{22}$.

La inversión privada en infraestructura pública no solo permite que recursos no estatales sean destinados a fines públicos, sino que, además, consiente el incremento de la inversión total o acumulada en infraestructuras. En consecuencia, se sostiene que la inversión privada no sustituye a la inversión pública, sino que se suma a ella. Este es el efecto denominado "adicionalidad" del financiamiento privado ${ }^{23}$.

Sin embargo, es importante preguntarse, junto con Engel y otros ${ }^{24}$, si acaso el financiamiento privado no podría ser obtenido directamente por el sector público mediante el mismo mecanismo utilizado por los concesionarios, esto es, endeudamiento. La cuestión es relevante porque el costo del endeudamiento del sector privado es, usualmente, mayor que el costo del endeudamiento del sector público. En efecto, es común que se critique a las APP porque su financiamiento es más costoso que la deuda pública. Esta objeción llega al punto de permitir que se afirme que podría recurrirse al financiamiento público incluso de obras cuya inversión será pagada por los usuarios y no por la Administración (como las autopistas de peaje) ${ }^{25}$.

Naturalmente, es posible encontrar literatura que cuestiona esta conclusión. Así, De Bettignies y Ross advirtiendo que la financiación privada puede ser el único camino disponible para los Estados que tienen cerradas las puertas del financiamiento a causa del excesivo endeudamiento de su sector público, sostienen que no puede compararse el costo del endeudamiento privado con el costo del endeudamiento público (y afirman que ello no es igual que comparar "manzanas con manzanas”). Concluyen que la tasa de endeudamiento del sector privado puede ser extremadamente baja si el mercado financiero considera el buen crédito del Estado donde operará la infraestructura. O sea, en la medida que el Estado receptor de las inversiones sea percibido como un "cliente" serio del concesionario, la financiación privada puede ser casi tan conveniente -en términos de tasa de interés- como la financiación pública ${ }^{26}$.

No obstante, la cuestión sigue abierta. ¿Qué justifica que la Administración decida recurrir a fórmulas concesionales si ellas son financieramente más costosas que la provisión pública de infraestructuras? Hay que recordar que este problema se presenta tanto en las concesiones tradicionales como aquellas en que la Administración es la única

\footnotetext{
${ }^{21}$ House of Lords, Select Committee on Economic Affairs, 2010, marginal 16.

${ }^{22}$ Fritzsche, 2009, p. 77; Chinyio y Gameson, 2009, p. 8; Davies, 2001, p. 4. Para España, Villar Rojas, 2007, p. 157.

${ }^{23}$ House of Lords, Select Committee on Economic Affairs, 2010, p. 9; Yescombe, 2007, p. 18.

${ }^{24}$ ENGEl et al., 2014, cap. 5.

25 Engel et al., 2014, p. 145; Esteban Galarza, 2006, p. 58; Mairal, 2013, p. 208.

${ }^{26}$ De Bettignies y Ross, 2004, pp. 146-147.
} 
demandante de los servicios. En este último caso, la problemática es solo más acuciante, toda vez que ese mayor costo será absorbido directamente por el presupuesto público y no por los usuarios de la obra.

La respuesta se puede encontrar en las indagatorias del Parlamento inglés que concluye que el costo de financiar un proyecto por medio de provisión tradicional será inevitablemente más bajo que el costo de financiamiento privado, ya que el Estado puede endeudarse a una menor tasa. Sin embargo, el argumento económico a favor del financiamiento privado no debe asentarse en ello, sino en su potencialidad para alcanzar un mejor value for money, sea por medio de ahorros en los costos de administración del proyecto, sea mediante la entrega de una infraestructura cualitativamente superior ${ }^{27}$.

Esto lleva a señalar que la condición necesaria para emprender una APP no es tanto la falta de recursos de parte del sector público (la que puede subsanarse recurriendo al endeudamiento, el que además tiene la ventaja de ser menos costoso que el endeudamiento privado), sino la mejor capacidad del concesionario de realizar las obras y prestar los servicios alcanzando una mejor relación de precio-calidad (un mejor value for money) de la que sería capaz de entregar un proyecto ejecutado por medio de provisión tradicional.

Esto cobra especial importancia, ya que ha habido casos en Inglaterra en los que la PFI ha sido usada inapropiadamente en proyectos que no han entregado un buen value for money ${ }^{28}$.

¿Cuál es la razón por la que las APP son capaces de mejorar la relación costo-calidad, el value for money, de los proyectos de infraestructura pública? La respuesta debe, aparentemente, buscarse en el rol que se asigna en estos proyectos al contratista privado.

\section{Participación privada ¿mayor eficiencia?}

Como sostienen Engel y otros, cuando se inició el ciclo del renovado entusiasmo político por las concesiones, junto con los argumentos de política fiscal (captación de recursos privados y adicionalidad de la inversión), se sostuvo que la sola participación del sector privado sería capaz de subsanar las deficiencias de la provisión pública de infraestructuras, manifestadas en la realización de obras fuera de plazo y presupuesto y en el pobre mantenimiento rutinario de las mismas, que se traducía en un servicio público de deficiente calidad ${ }^{29}$.

En otras palabras, se creyó que la sola circunstancia de dar espacio a la participación privada en el desarrollo y explotación de las infraestructuras de servicio público haría que estas se realizaran y se mantuvieran en mejores condiciones que si ello era ejecutado "directamente" por el sector público. Así, y en lo que dice relación con la PFI en el Reino Unido, el discurso político sostuvo que dicho mecanismo permitiría aprovechar las habilidades del sector privado en el desarrollo de proyectos complejos

\footnotetext{
${ }^{27}$ House of Lords, Select Committee on Economic Affairs, 2010, p. 12.

${ }^{28}$ HM Treasury, 2012, p. 21.

${ }^{29}$ ENGEL et al., 2014, p. 118.
} 
de infraestructura ${ }^{30}$. Esta actitud favorable hacia la participación del sector privado, en Estados Unidos, llegó a establecer una verdadera predilección a su favor en materia de ejecución de obras públicas ${ }^{31}$.

Las razones que explicarían este fenómeno se encuentran enunciadas en el trabajo de Yescombe $^{32}$. El argumento más recurrente dice relación con la intrínseca mayor eficiencia de la empresa privada que, buscando rentabilizar sus inversiones, se encuentra incentivada para culminar la infraestructura dentro de los plazos y dentro de los presupuestos que ella misma ha financiado para, de este modo, comenzar cuanto antes la explotación de la concesión. Merece la pena detenerse en este punto.

Es necesario preguntarse si es efectivo que el sector privado es intrínsecamente más eficiente que el sector público en la ejecución de infraestructuras. Para analizar este argumento, como ponen de relieve Engel y otros, no deben olvidarse dos cuestiones relevantes.

En primer lugar, las ganancias de eficiencia que se atribuyen al sector privado se traducen en su capacidad de rebajar los costos de realización y operación de la infraestructura, esto es, en un abatimiento de los costes de construcción, mantenimiento y explotación. El nudo gordiano de la cuestión es que la reducción de costos de explotación por parte de la industria privada podría verse traducida en la prestación de servicios de menor calidad, cuestión crucial en aquellas infraestructuras que se construyen, precisamente, para que el operador privado provea servicios al Estado (como es el caso de cárceles y hospitales) ${ }^{33}$.

En segundo término, se debe recordar que la construcción de obras públicas y el mantenimiento de las mismas, cuando se realiza por medio de contratos de obra o de prestación de servicios, también se hace recurriendo a empresas privadas. En otras palabras, el sector privado estará involucrado en la realización y mantenimiento de obras incluso cuando se hace por medio de provisión pública, porque la Administración del Estado ha dejado de contar con los equipamientos y el personal necesarios para la realización de obras de construcción ${ }^{34}$.

Debido a que hay opiniones doctrinales que cuestionan que el sector privado sea per se más eficiente que el sector público ${ }^{35}$, es admisible preguntarse cuál es la razón

${ }^{30}$ Davies, 2001, p. 5.

31 Grimsey y LeWis, 2004, p. 15.

32 Yescombe, 2007, pp. 21-24.

33 No hay que olvidar, tampoco, que el abatimiento de costos de explotación se puede traducir en condiciones laborales menos ventajosas para quienes trabajan en las actividades de prestación de servicios. Este argumento, que escapa a las finalidades de este artículo, ha sido abordado por HM TrEASURY, 2003, pp. 69-77.

${ }^{34}$ De Bettignies y Ross, 2004, pp. 138. Engel et al., 2014, p. 31, extreman el argumento destacando que las empresas privadas concesionarias o contratistas de obras públicas usualmente son las mismas empresas y que, por ello, "cualquier argumento que vincule las APP con ganancias de eficiencia debe ser más sutil” que la sola participación del sector privado.

35 Esteban Galarza, 2006, p. 48; Villar Rojas, 2007, p. 157. También Engel et al., 2014, p. 196, quienes califican de "ingenua" la idea de que la sola participación privada corrija las deficiencias del sector público. 
que hace o haría que la participación privada en la realización de infraestructura como concesionario sea más eficiente que esa misma participación privada (según Engel y otros, de las mismas empresas privadas) como contratistas de un contrato de obras públicas.

El argumento prácticamente unánime en la literatura nacional y comparada, como se verá en el siguiente apartado, no se relaciona estrictamente con la sola participación de la industria privada, sino con el modo en que se organiza su involucramiento en la ejecución de las obras, la prestación de los servicios y, a veces, en el diseño de las infraestructuras, esto es, encargando todas dichas prestaciones a un mismo sujeto (privado). Esto es conocido como bundling o integración de responsabilidades en el concesionario y, como se analizará, parece ser la causa de las ganancias de eficiencia que se atribuyen a la ejecución por vía concesional de las obras públicas.

\section{El bundling y el value for money: integración y eficiencia}

Si hay un punto en el que la abundante literatura extranjera se encuentra sustancialmente de acuerdo es que las ganancias de eficiencia que se generan con las APP no pueden atribuirse exclusivamente a la participación del sector privado, sino que son consecuencia del modo en el que se organiza su involucramiento en estas tareas públicas, esto es, confiando a un mismo contratista tanto el diseño como la construcción y explotación (o, al menos, la construcción y explotación) de la obra pública. Esta integración o bundling de tareas en manos de un mismo sujeto (normalmente, un consorcio de empresas especializadas en distintas áreas relacionadas con la obra y servicio público de que se trate) es la causa de un mayor value for money, es decir, de una mejora en la prestación de los servicios por un costo razonable.

En este apartado se analizarán los argumentos que buscan explicar este efecto y que, según la doctrina, sería suficiente justificación para emprender la ejecución de obras públicas por medio de APP.

En primer lugar, se debe considerar que la realización de una infraestructura pública tiene por finalidad la prestación de un servicio público de alta calidad y que se ajuste a un determinado presupuesto. En segundo lugar, la realización de dicha infraestructura supone la ejecución de varias actividades que pueden resumirse esquemáticamente en el diseño de la obra, su financiación, construcción y, finalmente, su explotación en la prestación del servicio.

La decisión que debe adoptar la autoridad encargada de la realización de estas obras dice relación con cuáles de dichas actividades se encomendarán al sector privado y cómo se organizará su prestación mediante un contrato. Debe determinar, además, en qué modo el contrato permitirá fiscalizar eficazmente el nivel de calidad de los servicios, así como cuáles mecanismos de incentivo y sanción se establecerán en el mismo para garantizar la observancia de dichos estándares de servicio.

De esta manera, por ejemplo, la Administración puede decidir encargar solo la construcción de la infraestructura al sector privado y su diseño, financiamiento y explotación a órganos públicos; en este caso estaremos frente a un esquema tradicional de provisión pública. Como se puede apreciar, el desarrollo de cada una de las fases de realización 
del proyecto se encuentra a cargo de sujetos distintos, de suerte que no se producirá integración en su ejecución. La misma situación se presentará si la Administración encomienda a distintos sujetos privados la realización de dichas tareas: a una empresa el diseño, a una segunda la construcción, y a una tercera la operación y mantenimiento de las obras. Acá, a pesar de la participación del sector privado en cada fase de desarrollo de la infraestructura tampoco se obtiene una integración de dicha participación, ya que se desagrega la realización de cada actividad en sujetos diversos.

Por otro lado, si se decide recurrir a un esquema de provisión concesional, la Administración encargará la financiación, construcción y operación de la infraestructura a un mismo sujeto (que el artículo 9 ${ }^{\circ}$, letra a), LCOP denomina "sociedad concesionaria”). De hecho, esta es la comprensión que nuestra legislación adopta del contrato de concesión, según este, la sociedad concesionaria debe financiar, construir -o reparar- y explotar la infraestructura. En este caso se verificará una de las principales características de las APP, esto es, la integración de responsabilidades por medio de la asignación de varias tareas a una única empresa ${ }^{36}$.

Entonces, el bundling no es sino la integración en la parte privada de todas (o casi todas) las etapas de diseño, construcción, financiamiento, mantenimiento y operación de una instalación, frecuentemente bajo la forma jurídica de una sociedad especialmente creada al efecto ${ }^{37}$. En virtud de un mismo contrato se encomienda a una contraparte privada la gestión global de una obra pública, desde su diseño (o desde su construcción) hasta la prestación de los servicios, en la etapa de explotación.

¿Qué hace que esta integración de tareas en un único contratista aumente la eficiencia de la prestación de los servicios? El argumento corriente señala que esta integración permitiría que los distintos procesos de ejecución de la infraestructura, sean concebidos uno en función del otro y, con ello, se realicen innovaciones e inversiones que permitirán un menor costo de mantenimiento y operación de la infraestructura, ya que "el empaquetamiento (...) propicia un comportamiento eficiente del agente privado" 38 .

Este comportamiento eficiente se traducirá, por ejemplo, en que la inversión en la construcción de la obra que realice el concesionario sea más elevada para que, durante la fase de explotación, se requiera un menor gasto de mantenimiento y operación. La misma situación se presentará cuando la concesión prevea el diseño, construcción y operación: en este caso el concesionario estará incentivado a introducir, ya en la etapa de diseño, innovaciones que permitan ejecutar una obra cuyo costo de mantenimiento sea más bajo.

Como se ve, la integración de responsabilidades permite que el concesionario adopte una perspectiva que tiene en consideración todos los costos del ciclo de vida de la infraestructura, esto es, los desembolsos que deberá realizar desde su concepción hasta el fin del período de explotación.

\footnotetext{
${ }^{36}$ De Bettignies y Ross, 2004, p. 138.

37 Grimsey y LEWIS, 2004, p. 129.

38 ENGEL et al., 2014, p. 130.
} 
La literatura da amplia razón de esto. La cámara alta del Parlamento inglés pone de manifiesto que el bundling estimula que el contratista realice una construcción más durable, que requiera menos mantenimiento en su ciclo de vida, lo que le permitirá recabar mayores rentabilidades y al Estado recibir mejores servicios por un precio adecuado (value for money) ${ }^{39}$.

¿Por qué se verificaría este efecto? La causa se encontraría en la complementariedad existente entre el diseño y la construcción y entre la construcción y la prestación de servicios: debido a que el concesionario deberá (diseñar), construir y mantener operativa la infraestructura tendrá incentivos para minimizar sus costos globales y no los de cada una de las fases de la ejecución contractual por separado. Por el contrario, si los procesos de decisión acerca de la realización de la infraestructura se escinden en distintos sujetos, estos incentivos desaparecen e, incluso, se crean incentivos contradictorios: por ejemplo, la reducción de los costos de construcción que el contratista buscará para verse adjudicado el contrato de construcción al menor precio, se encuentra en conflicto con la necesidad de minimizar los futuros costos de mantenimiento ${ }^{40}$.

Entonces, la opinión de la doctrina extranjera y de los cuerpos gubernativos que han analizado el resultado de las APP en distintas experiencias comparadas, indican que la condición más importante para alcanzar una mejor relación de costo y calidad es la integración de tareas y responsabilidades. En síntesis, la explicación de este efecto se encuentra en las ganancias de eficiencia que se producen al reunir los procesos de decisión y de ejecución de dichas decisiones en un mismo sujeto, permitiéndole tomar en consideración todos los costos del ciclo de vida de la infraestructura.

A la luz de lo anterior, se presenta la pregunta que es necesario formular e intentar responder para alcanzar los objetivos de este trabajo: ¿toda mayor eficiencia alcanzada por el concesionario es virtuosa para la prestación del servicio público y la satisfacción de los fines de interés general de la Administración? A causa de que los aumentos de eficiencia que pueda realizar el concesionario se traducirán en un abatimiento de los costos de explotación, ¿en qué casos dicho abatimiento de costos no afectará la calidad de la prestación de los servicios? ¿Qué infraestructuras admiten estas ganancias de eficiencia sin sufrir un correlativo detrimento en la calidad de los servicios que se prestan en o gracias a ellas?

Nuevamente es la teoría económica la que ayuda a esbozar una respuesta a esta inquietud que es fundamental para adoptar la decisión de dar en concesión, o no, la realización de una infraestructura.

Es en este punto donde cobra relevancia la calidad del contrato de concesión, esto es, la capacidad de las partes de diseñar un contrato que prevea con la mayor completitud posible sus obligaciones y derechos. Sin embargo, que el contrato prevea todas las situaciones que se presentarán a lo largo del extenso período de vigencia de una concesión es altamente improbable. De esta suerte, la teoría económica trabaja bajo

\footnotetext{
${ }^{39}$ House of Lords, Select Committee on Economic Affairs, 2010, p. 24; Yescombe, 2007, p. 21.

40 Bitrán y Villena, 2010, p. 208; de Bettignies y Ross, 2004, p. 144.
} 
el supuesto contrario, esto es, que los contratos de concesión son, indefectiblemente, "contratos incompletos" 41 .

Por ejemplo, Crocker y Masten ${ }^{42}$ sostienen que para determinar el mejor modo de establecer una relación entre proveedor y cliente (en nuestro caso, entre el Estado y el concesionario), cuando se encuentran involucradas inversiones en activos fijos utilizables para fines específicos (como son, precisamente, las obras que desarrolla el concesionario) se debe atender al nivel de complejidad que puede alcanzar la relación contractual en el futuro lejano, que es el horizonte al que miran las concesiones. Si hay incertidumbre, lo mejor es proceder a la integración vertical, esto es, que el cliente controle al prestador del servicio (en el caso de las concesiones, que el Estado controle a quien desarrolla los servicios públicos). La razón se encuentra en que, en estos casos de relaciones inciertas y complejas, los costos de transacción (en el caso de las concesiones, los costos de adaptación del contrato a las circunstancias imprevistas al tiempo de su celebración y, por ello, no reguladas en el contrato) son muy elevados y permiten que el prestador del servicio adopte conductas oportunísticas que se ven exacerbadas por su posición monopólica respecto de la prestación del servicio (justificada por su control sobre la infraestructura que ha construido y destina a la prestación del servicio). Aplicando este argumento, se puede afirmar que en aquellas concesiones que prestan servicios que pueden variar sustancialmente en el tiempo (piénsese en un hospital: ¿quién sabe cuántas personas demandarán el servicio en 20 o 25 años más y qué tipos de equipamientos existirán en ese entonces?), son poco propicias para asegurar una prestación económicamente eficiente del servicio y, por ello, en esta situación resulta más conveniente la integración vertical entre cliente y proveedor del servicio, esto es, la prestación pública del mismo, encomendando solo el diseño y realización de la edificación al sector privado, mas no su explotación.

A una conclusión fundamentalmente similar llega Hart ${ }^{43}$ quien, partiendo del supuesto que los contratos de concesión son todos incompletos y que, por tanto, durante la fase de explotación, inevitablemente, se presentarán conflictos entre las partes acerca de la calidad de los servicios que el concesionario preste en la infraestructura, concluye que la provisión tradicional (esto es, no integrada) es la opción adecuada si la calidad de la construcción puede ser bien especificada y el estándar de calidad de los servicios, por el contrario, no puede serlo. En cambio, una concesión será la vía propicia si la calidad del servicio que se pretende del concesionario puede ser bien especificada en el contrato inicial (o, más en general, cuando es posible acordar mecanismos eficientes para controlar la calidad del servicio y sancionar al concesionario cuando dicha calidad no se alcance o premiarlo cuando sí suceda), mientras que las características de la infraestructura son difíciles de establecer.

\footnotetext{
${ }^{41}$ Bitrán y Villena, 2010, p. 195; ENGel et al., 2014, p. 182.

42 Crocker y Masten, 1996.

43 HaRT, 2003 , p. 74.
} 
En su trabajo, Hart da algunos ejemplos: en el caso de cárceles y escuelas, determinar las características del edificio es sencillo, no así establecer contractualmente el tipo y estándar de los servicios; por tanto, en este caso, una concesión sería ineficiente debiendo privilegiarse la prestación del servicio por parte del Estado. En cambio, según Hart, sí sería posible establecer estándares de servicio para hospitales aun cuando sea difícil determinar las características físicas de la infraestructura: en este caso, las concesiones sí permitirían una ganancia de eficiencia. Esta conclusión, sin embargo, es debatible, como veremos en el párrafo sucesivo.

¿Cómo se enfrenta esta disyuntiva en nuestro derecho? ¿Cuenta la Administración chilena con instrumentos para discernir si las ganancias de eficiencia que se buscan con una concesión no impactarán en la calidad de los servicios prestados haciendo poco conveniente una concesión?

\section{La Administración Pública y la CUestión de Qué CONCESIONAR}

En este apartado pretendo analizar algunas normas de la legislación respecto de concesiones de obra pública que me permitirán concluir que la Administración Pública chilena cuenta con algunos instrumentos que le permiten discernir qué obras realizar bajo el sistema de concesiones (y cuáles no).

Antes, sin embargo, es posible reiterar una advertencia: la decisión última de proceder a la concesión de una infraestructura, o bien, a su realización mediante mecanismos tradicionales del contrato de obras públicas es una decisión de índole política. La prueba de ello se encuentra en la extensa polémica acerca de las concesiones de un cierto número de hospitales. Al efecto es importante recordar que, al concluirse el primer gobierno de Sebastián Piñera (marzo de 2014), fueron ingresados a trámite de toma de razón ante la Contraloría General de la República diversos decretos supremos de adjudicación de concesiones de infraestructura hospitalaria que fueron retirados de dicho trámite durante los primeros días del segundo mandato de Michelle Bachelet (2014-2018). Hoy, como vimos al inicio de este artículo, durante el segundo gobierno de Sebastián Piñera (2018-2022), el ministro de Salud ha anunciado la realización mediante concesiones de un elevado número de recintos hospitalarios. Como se puede advertir, acerca de qué concesionar no hay una respuesta, pues dicha respuesta viene de la política y ella entregará la que estime más adecuada a sus sensibilidades ideológicas.

Cuanto dicho no significa, sin embargo, que la Administración se encuentre desprovista de instrumentos para hacer que las obras concesionadas alcancen sus finalidades, esto es, procurar infraestructura de servicio público en el modo más acorde al interés general. Por tanto, a la Administración, en cuanto ejecutora de las decisiones del gobierno, le corresponderá emplear las herramientas que el ordenamiento jurídico le entrega para conseguir que la decisión política de concesionar una determinada infraestructura alcance los fines antes indicados.

La pregunta que debemos atender para concluir este trabajo es, pues, la siguiente: ¿cuenta nuestra Administración Pública con instrumentos jurídicos adecuados para 
implementar los criterios que la experiencia comparada reconoce como determinantes para alcanzar concesiones eficaces?

Prima facie, la respuesta es afirmativa. En primer lugar, por una razón de diseño institucional, es decir, gracias a la existencia de un órgano colegiado que presta asesoría al gobierno en materia de concesiones, el Consejo de Concesiones; en segundo lugar, por la relevancia que concede nuestra legislación a las bases de la licitación como la fuente primordial de la regulación de los contratos de concesión.

\section{El Consejo de Concesiones}

La reforma introducida a la LCOP por la Ley $\mathrm{N}^{\circ} 20.410$ instituyó un Consejo de Concesiones. Dicho órgano asesor cuenta con una composición y unas competencias que le permiten realizar una evaluación de las iniciativas de concesión que respondan a las directrices que, tanto la técnica como la experiencia comparada, han identificado como objetivos de estos contratos. La doctrina nacional, particularmente parca acerca de este organismo, ha celebrado el carácter primordialmente técnico de la instancia, cuestión que permitiría una mayor objetividad en las decisiones que debe adoptar ${ }^{44}$.

La institución de un consejo asesor en materia de concesiones había sido promovida por académicos nacionales como un mecanismo necesario para evaluar correctamente las concesiones antes de su implementación ${ }^{45}$. En efecto, Bitrán y Villena señalaban que una de las principales fallas del sistema de concesiones nacional se encontraba en que "la institucionalidad que se ha estructurado no genera la disciplina, transparencia e incentivos adecuados para asegurar la eficiencia y eficacia” de las concesiones. En cuanto dice relación con la finalidad del Consejo, estos autores indican que su objetivo será, gracias a la presencia de expertos independientes, "reducir el riesgo de captura y el sesgo de la autoridad a favor de la infraestructura per se" 46.

La composición del órgano ${ }^{47}$, en efecto, permite predecir o, al menos, intuir un cierto grado de desapego o distancia de las directrices estrictamente políticas que guían las decisiones en materia de desarrollo infraestructural. La presencia de académicos (dos designados por el ministro de Hacienda y dos por el ministro de Obras Públicas) debiera introducir en las deliberaciones del Consejo sensibilidades a los argumentos y consideraciones de orden técnico que permitan adoptar decisiones apropiadas a los fines de la concesión y que balanceen los criterios propiamente políticos que expresarán los demás consejeros (uno, el presidente del Consejo, designado en conjunto por el ministro de Obras Públicas y el ministro de Hacienda y, el segundo, el propio ministro de Obras Públicas).

\footnotetext{
${ }^{44}$ Camacho Cepeda, 2014.

45 Bitrán y Villena, 2010, p. 210.

46 Bitrán y Villena, 2010, pp. 209-210.

47 Art. $1^{\circ}$ bis D.S. MOP $\mathrm{N}^{\circ}$ 900/1996, cuyo inciso $1^{\circ}$, relativo a la composición del Consejo, fue modificado por la Ley N 21.044 que creó la Dirección General de Concesiones de Obras Públicas que, además, alteró su composición.
} 
Entre las competencias consultivas de este Consejo se cuentan algunas relevantes para los fines de este trabajo. En efecto, de acuerdo con el art. $1^{\circ}$ bis LCOP, el Consejo está encargado de informar "acerca del tipo de infraestructura que se desarrollará al amparo de [la] ley, de los proyectos y de las modalidades de régimen concesional”. En este mismo sentido, las letras c) y f) del mismo artículo establecen que el Ministro de Obras Públicas requerirá del informe previo del consejo cuando se deban analizar "proyectos de iniciativa pública que se considerará ejecutar mediante el sistema de concesión regulado en esta ley", así como de "las modalidades del régimen concesional de los proyectos que se someterán a licitación pública”.

Estas normas admiten ser leídas como una unidad, de suerte que el ministro de Obras Públicas debe consultar al Consejo de Concesiones respecto de las obras que se pretenda llevar a cabo mediante el sistema regulado por la Ley de Concesiones.

Así, en virtud de estas competencias, el Consejo podrá emitir su parecer acerca de la naturaleza (el "tipo") de infraestructura que se entregará en concesión, esto es, acerca de la clase de proyecto que se pretende licitar y concesionar. En este punto cobra relevancia cuanto señalado acerca de la integración entre las obras y los servicios que se prestarán gracias a la nueva infraestructura. En efecto, si el Consejo debe pronunciarse por el tipo de obra que será entregada en concesión podrá considerar que aquellas infraestructuras en las que el estándar de los servicios es difícil de definir -como las infraestructuras de servicios hospitalarios, penitenciarios y educacionales-, no son apropiadas para este tipo de explotación, precisamente, porque las mejoras de eficiencia que puede alcanzar el concesionario en la etapa de explotación de la infraestructura pueden traducirse en rebajas de la calidad de los servicios que se prestan a los pacientes, a los reclusos o a los educandos.

Por ello, es valioso recordar que la doctrina nacional afirma que "la provisión pública es la forma organizacional preferida cuando la calidad es la principal preocupación y no es contratable. El problema es básico en muchos servicios públicos. Para definir estándares 'objetivos' se deben traducir las metas a una escala mensurable [... y ello... ] puede ser muy difícil e incluso imposible cuando los servicios son complejos y las metas ambiguas, como el caso de educación, salud, cárceles y servicios de tecnología de la información” ${ }^{4}$.

En consecuencia, la exigencia legal de obtener el parecer del Consejo de Concesiones antes de iniciar un proceso de licitación de un contrato de concesión, en relación con el tipo de infraestructura y las modalidades que adoptará el régimen concesional específico, permite que, en el proceso de decisión, se consideren suficientes aspectos técnicos, económicos y jurídicos como para reducir la probabilidad de que se sometan a licitación obras que no se adapten a las características identificadas por la experiencia internacional y reseñadas en este trabajo.

La necesidad de este tipo de análisis ex ante fue puesta en evidencia por Bitrán y Villena poco antes de la dictación de la Ley N 20.410, de 2010. En su trabajo destacan que el sistema de concesiones chileno, cuyos actores se encontraban más concentrados

\footnotetext{
${ }^{48}$ ENGEl et al., 2014, p. 209.
} 
en realizar infraestructuras que en definir o controlar el estándar de prestación de los servicios que dichas infraestructuras prestan, tenía un déficit relevante a la hora de decidir qué tipo de obras entregar en concesión: no se realizaba una evaluación económica de los proyectos con financiamiento privado, esto es, "no se comparan sistemáticamente los costos y beneficios de esta alternativa con la opción tradicional de inversión pública" 49 .

\section{Las bases de licitación y la Dirección General de Concesiones}

El principal mecanismo con que cuenta la Administración del Estado para asegurar la satisfacción del interés general comprometido en el contrato de concesión son las amplias facultades que le entrega el ordenamiento jurídico para regular la relación jurídica por medio de las bases de licitación.

La normativa esencial en este aspecto es el art. $1^{\circ}$ LCOP, el que concede un rol central en la regulación de cada específico contrato a las bases de la licitación, las que deben establecer, además, los niveles de servicio y estándares técnicos que deberá cumplir el concesionario.

No es esta la oportunidad para recordar el rol que cumplen las bases de licitación en un contrato administrativo, como el contrato de concesión. Al efecto, bastará recordar que las bases de licitación o pliegos de condiciones son los documentos que contienen el conjunto de requisitos, condiciones y especificaciones que describen el objeto contractual así como los derechos y obligaciones que adquirirán las partes del mismo ${ }^{50}$.

Las normas de la ley y el reglamento entregan a las bases de licitación un rol central en la regulación del contrato de concesión, razón por la que este instrumento normativo es crucial para fijar los criterios y mecanismos de fiscalización de los niveles de servicios y estándares técnicos que se deben observar por el concesionario.

Es fundamental destacar en este punto el reforzamiento de la institucionalidad que significó la creación, por parte de la Ley $\mathrm{N}^{\mathrm{o}}$ 21.044, de la Dirección General de Concesiones de Obras Públicas.

A esta unidad del Ministerio de Obras Públicas ha sido encomendada, entre otras funciones, "velar por el adecuado y correcto cumplimiento de los contratos de concesión en sus diferentes etapas" teniendo en cuenta, para ello, entre otros aspectos, las bases de licitación (art. 22 ter, letra e), DFL MOP N 850/1997). En virtud de esta competencia se concentra en una nueva Dirección del MOP la fiscalización del cumplimiento de las obligaciones adquiridas por parte de los concesionarios.

Si bien la creación de esta Dirección General resulta adecuada desde el punto de vista de la fortaleza orgánica en materia de concesiones, su condición de organismo dependiente del Ministerio de Obras Públicas no satisface las exigencias de independencia política que autores nacionales vienen sugiriendo para reforzar la gobernanza en

49 Bitrán y Villena, 2010, p. 189.

50 Véase, en general, Moraga KLenner, 2007, p. 155 y la definición del art. $3^{\circ} \mathrm{N}^{\circ} 4$ del D.S. MOP No 956/1997, Reglamento de la LCOP. 
esta materia. Así, tanto Bitrán y Villena como Engel y otros ${ }^{51}$ abogan por la creación de una Superintendencia de Obras Públicas encargada de supervigilar las prestaciones de los contratistas de obras públicas en modo independiente de la agencia que diseña y adjudica los contratos de concesión. La separación de estas funciones (adjudicación y fiscalización del cumplimiento de los contratos) es, según estos autores, una necesidad para efectos de garantizar adecuadamente la satisfacción de los fines de los contratos de concesión: el cumplimiento de los estándares y niveles de servicio es un aspecto clave para establecer la eficacia de la política concesional.

De esta manera, la importancia de los aspectos recién señalados es indudable en todas las concesiones, incluso en aquellas que adoptan el tradicional modelo de pago del usuario por uso de la infraestructura, pero adquieren una relevancia aun mayor cuando se trata de aquellas concesiones en las que el único "cliente" del concesionario es la Administración Pública. Ya se ha identificado este tipo de concesiones como aquellos acuerdos en donde la remuneración del concesionario proviene únicamente de pagos realizados por la Administración concedente. En este tipo de concesiones, por la complejidad del tipo de servicios que presta el concesionario, la fiscalización del cumplimiento de los estándares técnicos y de los niveles de servicio adquiere una importancia singular.

Por una parte, como evidencian Bitrán y Villena, el sector público tiene un sesgo a favor de las infraestructuras, es decir, una inclinación a preocuparse por construir antes que por efectuar mantenimiento, lo que se traduce en la "inexistencia de monitoreo de los servicios comprometidos en los contratos [ya que] la autoridad no tiene incentivos para invertir en fiscalización, pues está concentrada en el desarrollo de nuevas inversiones" en obras 52 .

Esta es la razón por la que las condiciones contractuales establecidas en las bases de licitación son tan relevantes: porque en la medida que se establezcan medidas eficaces de control y verificación de los servicios se podrá subsanar este sesgo favorable respecto de la creación de nueva infraestructura y correlativo desinterés por el monitoreo de la calidad de los servicios.

Sin embargo, resulta interesante constatar de la lectura de las bases de licitación que las medidas de control de calidad son escuetamente reguladas y los mecanismos de fiscalización son de eficacia limitada, dejando entregada a los informes y reportes elaborados por el mismo concesionario el control de varios aspectos de la calidad de los servicios prestados ${ }^{53}$.

El control de la calidad de los servicios es necesario no solo por la obvia razón de que el Estado es quien paga por ellos, sino también porque si no se verifica que ellos alcancen el estándar establecido en el contrato se atenta contra la finalidad misma de la

${ }^{51}$ Bitrán y Villena, 2010, p. 207 y ss.; Engel et al., 2014, p. 200 y ss.

52 Bitrán y Villena, 2010, p. 201.

53 Véanse, por ejemplo, el artículo 1.10.5 de las bases de la licitación de la concesión de los Hospitales de Maipú y La Florida, así como el artículo 1.10.2.11 de las bases de licitación de la concesión de infraestructura penitenciaria grupo 3 (cárceles de Santiago 1, Valdivia y Puerto Montt), donde la fiscalización es confiada exclusivamente a la elaboración de informes de resultados de las prestaciones convenidas. 
concesión, esto es, una prestación de servicios de calidad en modo eficiente. En efecto, "pese a que el empaquetamiento implícito en las APP debería llevar a un mejor mantenimiento y a minimizar los costos del ciclo de vida de la obra, se requiere de una agencia pública que monitoree y haga cumplir los estándares de servicio" 54.

$\mathrm{Y}$ es en este punto donde surge la tesis central que se quiere afirmar en este artículo: que, a pesar de existir los mecanismos institucionales y contractuales para hacer posible una APP eficiente y capaz de satisfacer los intereses públicos, hay concesiones en que la intrínseca complejidad de los servicios que debe desarrollar el concesionario, la ausencia de una agencia pública encargada de fiscalizar y monitorear su calidad (una superintendencia), así como el diseño de mecanismos contractuales ineficaces para el control de la calidad de las prestaciones del concesionario, hacen improbable que la autoridad logre controlar adecuadamente su nivel de calidad. Como dicen Engel y otros: "si la calidad del servicio no es contratable, la parte privada podría bajar sus costos reduciendo la calidad del servicio", por este motivo, "si la calidad no es contratable, y es la principal preocupación de la política pública, entonces la provisión pública probablemente sea la forma organizacional apropiada". ${ }^{55}$.

En este punto no queda más que recordar cuánto concluía Hart acerca de la relevancia de determinar y fiscalizar la calidad de los servicios que preste la infraestructura: la provisión tradicional es la opción adecuada si el estándar de calidad de los servicios no puede ser especificada ${ }^{56}$. Ello ocurre, como sostienen Engel y otros y Bitrán y Villena, en las infraestructuras de tipo social, esto es, las obras destinadas a la prestación de servicios de naturaleza sanitaria, carcelaria y educacional ${ }^{57}$.

\section{CONCLUSiones}

1. El presente artículo ha intentado sostener que la política de desarrollo de infraestructura por medio de contratos de concesión no admite que cualquier obra pueda ser concesionada. Para determinar la pertinencia de una concesión es imprescindible atender al tipo de servicios que prestará la infraestructura.

2. El tipo de servicios que prestará la obra determina la modalidad de remuneración del concesionario. Ello hace surgir dos grandes modelos de remuneración: el "pago por uso", propio de las autopistas y, en general, de las infraestructuras de transporte; y el pago por medio de subsidios, modelo en el que es la Administración quien remunera directamente al concesionario por los servicios que recibe gracias

\footnotetext{
${ }^{54}$ ENGEL et al., 2014, p. 197.
}

55 Engel et al., 2014, p. 197 y 124. En el mismo sentido, Villar Rojas, 2007, p. 170 quien sostiene que "en cuanto a los contratos de concesión de obra pública sanitaria, la delimitación de los derechos y deberes resulta de más difícil calificación por su complejidad".

56 HART, 2003, p. 74.

57 Bitrán y Villena, 2010, p. 195; ENGel et al., 2014, p. 209. 
a la infraestructura desarrollada. Es a esta modalidad del contrato de concesión a la que se ha denominado "asociación público-privada” en este artículo.

3. La concesión de este tipo de obras se encuentra rigurosamente condicionada por la posibilidad de que, gracias a la concesión, se alcance una prestación de servicios públicos más eficiente, esto es, económicamente ventajosa para el Estado, quien, además, recibirá servicios que redundarán en la mejor satisfacción del interés general.

4. Para que se produzca este efecto es imprescindible que se presente una integración en las etapas de diseño, construcción y explotación de la obra con el objeto de reducir el costo del ciclo de vida de la infraestructura y que se establezcan estándares de calidad de servicio objetivos y mensurables. Además, es necesario que la Administración cuente con instancias de fiscalización eficaces de la calidad de dichos servicios.

5. Dicha situación no se presenta en el caso de las infraestructuras de tipo social (penitenciario, sanitario, educacional) donde las ganancias de eficiencia del concesionario, que se traducen en una reducción de los costos de explotación, pueden tener un impacto negativo en la calidad de los servicios desarrollados por el concesionario.

6. En consecuencia, el modelo de provisión de infraestructura por medio de APP está sujeto a severos cuestionamientos cuando se trata de servicios cuya calidad resulta difícil de medir objetivamente y fiscalizar de manera adecuada.

7. En suma, puedo concluir que las concesiones de cárceles, hospitales, escuelas y otras infraestructuras destinadas a la prestación de servicios en extremo sofisticados y de difícil fiscalización por parte del Estado debieran ser desarrolladas mediante provisión pública, en especial frente a la ausencia de una autoridad o agencia independiente (Superintendencia de Obras Públicas) encargada de fiscalizar el cumplimiento de los estándares de servicio por parte de los concesionarios y a la baja calidad de los mecanismos contractuales de control de dichos estándares.

\section{BIBLIOGRAFÍA}

Bitrán, E.; Villena, M., 2010: “El nuevo desafío de las concesiones de obras públicas en Chile”, Revista Estudios Públicos 117.

Camacho Cepeda, G., 2014: "Las novedades de la Ley N²0.410 en la regulación de las concesiones de obra pública en Chile", Revista iberoamericana de derecho administrativo y regulación económica 9.

Chinyio, E.; Gameson, R., 2009: "Private Finance Initiative in Use”, en Akintoye, A., Beck, M. (Eds.), Policy, Finance E Management for Public-Private Partnerships. Wiley-Blackwell, Oxford.

Crocker, K.J.; Masten, S.E., 1996: "Regulation and Administered Contracts Revisited: Lessons from Transaction-Cost Economics for Public Utility Regulation", Journal of Regulatory Economics 9.

Davies, A., 2001: Accountability. A Public Law Analysis of Government by Contract, Oxford University Press, Oxford.

De Bettignies, J.-E.; Ross, T.W., 2004: “The economics of public-private partnerships", Canadian public policy - Analyse de politiques 30. 
Engel, E.; Fischer, R.; Galetovic, A., 2014: Economía de las asociaciones público-privadas. Una guía básica, Fondo de Cultura Económica, México.

Engel, E.; Fischer, R.; Galetovic, A., 2001: "El programa chileno de concesiones de infraestructura: evaluación, experiencias y perspectivas”, en Larraín, F.; Vergara, R. (Eds.), La transformación económica de Chile. Centro de Estudios Públicos, Santiago.

Esteban Galarza, M., 2006: "La colaboración público privada en la provisión de infraestructuras: una valoración de la experiencia internacional”, Ekonomiaz, Revista Vasca de Economía 63.

Fritzsche, M., 2009: "Does PPP Need Financing? Considerations for Integrating and Structuring Financing into PPP Projects", European Public Private Partnership Law Review 4.

Grimsey, D.; Lewis, K.M., 2004: Public-Private Partnerships. The worldwide revolution in infrastructure provision and project finance, Edward Elgar Publishing, Cheltenham-Northhampton (Mass).

Guasch, J.L., 2004: Granting and Renegotiating Infrastructure Concessions: Doing It Right, The World Bank, Washington (DC).

HART, O., 2003: "Incomplete contracts and public ownership: remarks, and an application to public-private partnerships", The Economic Journal 113.

HM Treasury, 2012: A new approach to public private partnerships. H M Stationary Office, London.

HM Treasury, 2003: PFI: meeting the investment challenge. H. M. Stationary Office, London.

House of Lords, Select Committee on Economic Affairs, 2010: Private finance projects and off-balance sheet debt, H. M. Stationary Office, London.

La Tercera, 2018: "Minsal evalúa construir entre 13 y 17 hospitales, todos concesionados".

Autor, 2019: “Las concesiones de obra pública: ¿qué son y por qué se utilizan en Chile?”, Revista Derecho del Estado [aceptado].

Loo Gutiérrez, M., 2015: "Las asociaciones público-privadas en la Unión Europea: Elementos para un análisis sobre la concesión de obra pública en Chile", Revista de Derecho de la Pontificia Universidad Católica de Valparaíso 45, 313-337.

MAgide, M., 2016: "Instrumentos contractuales de Colaboración Público-Privada para la Provisión de Infraestructuras Públicas en el Derecho Español”, Revista de derecho administrativo (PUCP) 16.

Mairal, H.A., 2013: "Los riesgos en la financiación privada de proyectos públicos", Revista de derecho administrativo (PUCP) 13.

Ministerio de Obras Públicas, 2016: Concesiones de obras públicas en Chile: 20 años, MOP, Santiago.

Moraga Klenner, C., 2007: Contratación administrativa, Editorial Jurídica de Chile, Santiago.

Puerta Seguido, F., 2008: "El contrato de concesión de obra pública. La génesis de su regulación, definición legal y objeto", en Puerta Seguido, F. (Ed.), El contrato de concesión de obras públicas en la Ley de contratos del sector público. La Ley, Madrid.

RAmírez BARría, N., 2018: Análisis crítico del programa de concesiones de infraestructura carcelaria, Memoria de licenciatura, Facultad de Derecho PUCV, Valparaíso.

SAdKa, E., 2006: Public-Private Partnerships: A Public Economics Perspective, International Monetary Fund, New York.

Villar Ezcurra, J.L., 2004: “Las infraestructuras públicas”, en Ariño Ortiz, G. (Ed.), Principios de derecho público económico. Comares, Granada.

Villar Rojas, F.J., 2007: "La concesión como modalidad de colaboración privada en los servicios sanitarios y sociales", Revista de Administración Pública 172.

Yescombe, E.R., 2007: Public-private partnerships: principles of policy and finance, Butterworth Heinemann, Oxford. 